\title{
The ratio of response spectra from seismic-type free-field and building foundation vibrations: the influence of rockburst parameters and simple models of kinematic soil-structure interaction
}

\author{
Krystyna Kuzniar ${ }^{1}$ (D) Tadeusz Tatara $^{2}$ (D)
}

Received: 24 May 2019 / Accepted: 9 October 2019 / Published online: 19 October 2019

(C) The Author(s) 2019

\begin{abstract}
Mining-related seismicity is a significant problem in regions with the exploitation in underground mines. Despite the fact that mining tremors result from human activity and are classified as so-called paraseismic shocks, as with earthquakes, they are random events. Moreover, these rockbursts could cause significant damage to surface structures, including buildings. This paper deals with the analysis of experimentally obtained results in terms of the differences between the mine-induced vibrations described by the response spectra from the free-field near a given building and the simultaneously recorded vibrations in the building foundations. The influences of epicentral distance, mining tremor energy and the value of peak ground acceleration on the curves of free-field-foundation response spectra ratio were studied. The impact of the type of building on the transmission of response spectra from the free-field vibrations to the building foundations was also analysed for three types of apartment buildings (low-rise, medium-rise, high-rise). The usefulness of the approximate models of the phenomenon of soil-structure interaction during earthquakes proposed in the literature is also estimated in this paper in specific instances of mining tremors. Furthermore, the study presents original, simple, empirical models for the evaluation of the differences in the response spectra originating from free-field and building foundation vibrations in the mining region.
\end{abstract}

Keywords Mining-induced rockbursts $\cdot$ Free-field vibrations $\cdot$ Building foundation vibrations $\cdot$ Response spectra $\cdot$ Soil-structure interaction $\cdot$ Empirical models

Krystyna Kuzniar

krystyna.kuzniar@up.krakow.pl

Tadeusz Tatara

ttatara@pk.edu.pl

1 Institute of Technology, Pedagogical University of Cracow, Kraków, Poland

2 Faculty of Civil Engineering, Cracow University of Technology, Kraków, Poland 


\section{Introduction}

There are two major sources of surface vibrations that affect buildings. The main, most intense source of free-field vibrations is natural earthquakes. However, ground motions can also be induced by so-called paraseismic sources originating, for example, from both underground and surface mining, pile driving, driving sealed walls and surface and underground traffic.

Mining originating surface vibration differ substantially from other human-induced, seismic-type vibrations. Rockburst is a random phenomenon, and it is out of human control regarding the time and location of occurrence, and magnitude, as is with earthquakes (Maciag et al. 2016; Zembaty 2004). Mining-related free-field vibrations are the most intensive phenomena in comparison with other paraseismic events.

Surface vibrations caused by earthquakes and mining shocks have many similarities but also differ in several aspects (Maciag et al. 2016; Pachla et al. 2019; Zembaty 2004). The major differences concern the duration of the intensive vibration phase, values of peak ground acceleration (PGA) (Furumura et al. 2011), content of predominant frequencies (Maciag et al. 2016), frequency of occurring and depths of hypocentre (Kufner et al. 2017), the composite parameter $P G V^{2} / P G A ; P G V$ - peak ground velocity (PinedaPorras and Ordaz 2012).

In recent years, the risk of mine-induced seismicity hazard has increased because of visible increases of activity in mining. Mining-induced free-field motion is a hazard to surface structures, as ground motions can result in them being damaged (Deck et al. 2003; Khosravikia et al. 2018; Singh and Roy 2010). Active mining-induced seismicity is important problem in mining areas in countries on different continents, for example in Asia (Li et al. 2007; Lu et al. 2012; Srinivasan et al. 1999), in Australia (Poplawski 1997), in Africa (Steward et al. 2001), North America (Arjang and Herget 1997) and in Europe (Konicek et al. 2013, Lovchikov 2013; Maciag et al. 2016).

The random nature of mining rockbursts occurrence causes significant problems with regard to their analysis. Moreover, soil-structure interaction (SSI) results in difficulties in assessment and prediction of the impact of mining-related vibrations on buildings (Deck et al. 2003; Fu et al. 2018; Güllü and Karabekmez 2017). This is due to significant differences in the simultaneously recorded free-field vibration next to the building, the building motions, and in the corresponding response spectra, e.g. observed in Legnica-Glogow Copperfield (LGC) region, which is the one of mining area most threatened with seismicity in Poland (Maciag et al. 2016).

It should be emphasized that the SSI phenomenon discussed in this paper, resulting in the differences in the free-field and building vibrations simultaneously recorded at the same time, is related to kinematic soil-structure interaction. As it is known, it is one of the two types of interaction which concerns the changes in the foundation input motion, as well as the foundation dynamic stiffness. The second type of interaction, named inertial interaction, relates to dynamic response of the soil-structure system in connection with inertial forces. Combined effects of kinematic interaction and inertial interaction, were investigated by e.g. Ahmadi (Ahmadi 2019a, b).

Standard design response spectra given in seismic codes (e.g. EN 1998-1 Eurocode 8 2004; NSR-10 2010; GBDS 2018) are formulated using the measurements of free-field vibrations. However, the results given in (Maciag et al. 2016), indicate that a more accurate assessment of the harmfulness of mine-induced vibrations to buildings is obtained 
using recorded building foundation vibrations. Therefore, it is desirable to predict and assess the vibration transfer from free-field to buildings foundations.

The amount of mining-related vibration transition from free-field to the building foundation, in the case of maximum vibration values [velocity $(P G V)$, acceleration $(P G A)$ ], depends on many parameters: the energy of rockburst $(E n)$, the epicentral distance ( $r e$ ), the way (direction) of seismic wave, the maximum value of ground vibrations, the building vibration direction, and the free-field vibration dominant frequency. It is proved in many papers (Fu et al. 2018; Kuzniar et al. 2018) on the basis of the analysis of recorded vibrations. Nevertheless, it should be emphasized that using the maximum values of vibrations ( $P G V$ or $P G A$ ) is a significant simplification in research of SSI, in comparison to the application of response spectra as well as ratio of response spectra (RRS) (FEMA 2005; Fu et al. 2018; Maciag et al. 2016; NIST GCR 2012).

Simple approximate models for practical use in evaluating the transmission of seismic vibrations from the free-field to the building foundation are proposed in FEMA (2005), Mylonakis et al. (2006) and NIST GCR 2012. The suitability (with regard to accuracy) of these models proposed in the literature for vibrations of seismic origin has been the subject of preliminary analysis with regard to vibrations caused by mine-induced rockbursts in the LGC region (Kuzniar and Tatara 2015). This issue is continued and developed in this paper.

This paper analyses the results of in situ measurements of mine-induced surface vibrations in the LGC region-to focus on assessing the impact of mining rockburst parameters ( $r e$ and $E n$ ), parameters of free-field vibrations ( $P G A$ ), and the type of building on the curve relationship (ratio) of response spectra $(R R S)$ from simultaneously measured free-field vibrations and building foundation vibrations in the case of actual, typical lowrise, medium-rise and high-rise apartment buildings. Dimensional response spectra $\left(S_{a}\right)$ from horizontal vibrations were taken into account; on the basis of these, the relationship $R R S\left(S_{a}\right)$ was calculated.

Besides, the study proposes $\operatorname{RRS}\left(S_{a}\right)$ empirical models to determine the differences in the dimensional acceleration response spectra $\left(S_{a}\right)$ from the ground and building foundation vibrations in the LGC area. The proposed simple models are based and verified using the in situ measurements.

\section{Measurements of surface vibrations at the Legnica-Glogow Copperfield (LGC)}

The monitoring of free-field and building vibrations began in LGC area in 1989. In total, there were over thirty seismic measurement stations registering free-field and building vibrations. Measurement equipment recording the horizontal and vertical components of vibration accelerations (in the majority of seismic stations), are placed in the free-field, on the foundation of buildings and on the upper storeys. The dynamic measurements of the vibrations were realised by the measuring system consisted of PCB acceleration sensors and appropriate instrumentation. The installed measuring equipment records the vibrations in the frequency range from 0.5 to $100 \mathrm{~Hz}$, and the maximum acceleration is $3 \mathrm{~m} / \mathrm{s}^{2}$. Detailed descriptions of the measurement stations, the apparatus used, the mining shock characteristics, are presented in previous papers (Maciag et al. 2016; Olszewska 2017).

In this paper, hundreds of rockbursts with energy levels $(E n)$ within the range $1 \times 10^{6}-2 \times 10^{9} \mathrm{~J}$ and with epicentral distances $(r e)$ with reference to the analysed buildings 
within the range $270-5839 \mathrm{~m}$ are considered. The study refers to horizontal components of peak ground accelerations $(P G A)$ larger than $10 \mathrm{~cm} / \mathrm{s}^{2}$. The calculated values of the $P G A / P G V$ ratio depending on the energy of mining shocks, are presented in Table 1.

For the analysed energy ranges of rockbursts (order of magnitude: E7, E8 and E9 [J]), one can state that the lower values of the $P G A / P G V$ ratio are within the range corresponding to natural earthquakes. Mining tremors causing surface vibrations with low $P G A / P G V$ ratios are characterised by the highest energy levels and can have harmful effects on building structures.

During the research of free-field vibrations caused by mining tremors, buildings foundation vibrations were simultaneously measured at several measuring stations. Two horizontal components and a vertical component of vibrations were recorded. The vertical component of vibration was neglected in analysis due to the weight of the analysed buildings. The weight of buildings significantly exceeds the load resulting from the operation of the vertical component of mine-induced vibrations.

Vibrations of foundations of buildings were measured in three apartment buildings, each with a basement. The foundations of all of the buildings consist of concrete strips on a depth of $1.5 \mathrm{~m}$. The buildings are located close together in the area of one housing estate. The examined buildings were: (a) low-rise, two-story, masonry house with plan dimensions of $10 \mathrm{~m} \times 10 \mathrm{~m}$, denoted as L; (b) medium-rise, five-story building erected using multi-tube large-block technology, denoted as $\mathrm{M}$-the building has plan dimensions of $100.1 \mathrm{~m} \times 11.7 \mathrm{~m}$ (multiple-segment), vertical load-bearing walls constitute a mixed transverse-longitudinal system; (c) high-rise, twelve-story building with a transverse-longitudinal, load-bearing, large-plate wall system, denoted as $\mathrm{H}-$ the $\mathrm{H}$ building has plan dimensions of $54.6 \mathrm{~m} \times 10.8 \mathrm{~m}$ (two-segment). Figure 1 shows simplified cross sections of the buildings and their projections. Additionally, the sub-soil layers under the foundations of building L are presented in Fig. 2 as an illustration of the geological profiles in the location of the buildings. In the whole area, there is bedrock below $350 \mathrm{~m}$.

Because of the considered buildings being of various types, they have different natural fundamental frequencies. The frequencies were experimentally determined using results of in situ measurements. Filtered records were considered and then Power-spectral density (PSD), cross-spectral density (CSD) between the set of signals and fast Fourier transform (FFT) algorithms were applied (The Math Works 2000). The measured fundamental natural frequencies of the investigated buildings in horizontal directions, frequencies $f_{1 x}$ and $f_{1 y}$ in transverse $(x)$ and longitudinal $(y)$ directions, respectively, are listed in Table 2 (Maciag et al. 2016).

A total of 251 pairs of simultaneously recorded free-field-foundation accelerations were taken into account. Accelerometers on the free-field were placed a few meters away from each of the analysed buildings to exclude the impact of the building on the recorded free-field vibrations. Acceleration records of free-field vibrations next to the building and on the building foundation were measured using so-called 'armed partition' accelerometers, for each of the considered mining shocks. Table 3 displays the

Table 1 Values of $P G A / P G V$ ratio for mining tremors

\begin{tabular}{ll}
\hline Energy $[\mathrm{J}]$-order of magnitude & $P G A / P G V[-]$ \\
\hline E7 & $20-105$ \\
E8 & $25-87$ \\
E9 & $8-20$ \\
\hline
\end{tabular}


(a)

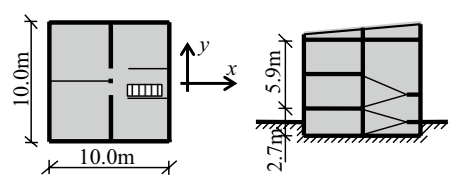

(c) (b)

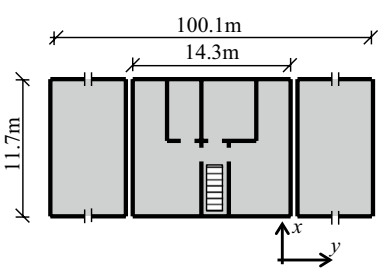

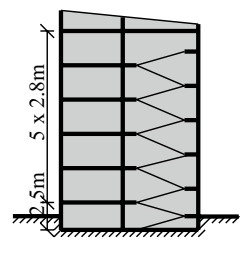
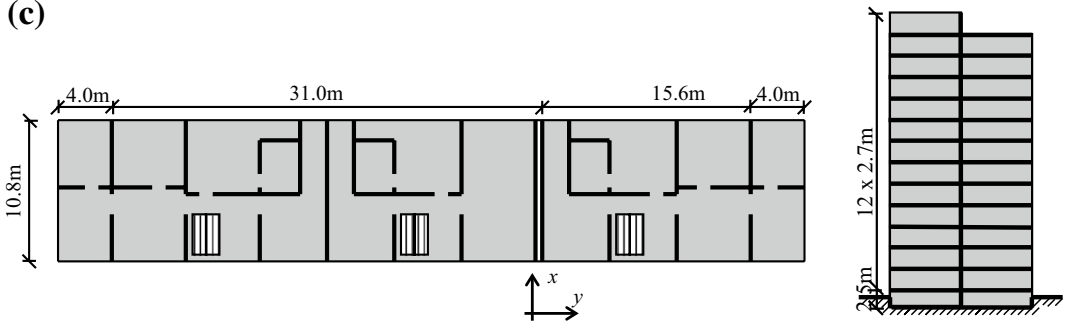

Fig. 1 Cross sections of the buildings and their plans: a $\mathrm{L}$ building; $\mathbf{b} \mathrm{M}$ building; $\mathbf{c} \mathrm{H}$ building

Fig. 2 Sub-soil layers under the foundations of building $\mathrm{L}$

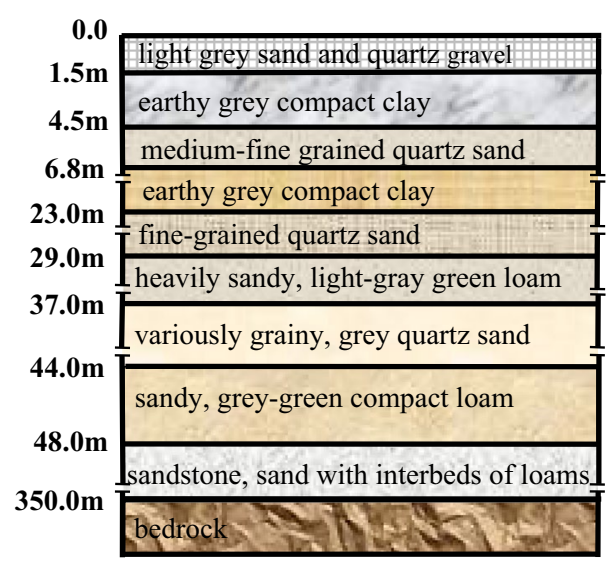

Table 2 Fundamental natural frequencies of horizontal vibrations of the analysed buildings

\begin{tabular}{lll}
\hline Building & $f_{1 x}[\mathrm{~Hz}]$ & $f_{1 y}[\mathrm{~Hz}]$ \\
\hline $\mathrm{L}$ & 6.3 & 6.4 \\
$\mathrm{M}$ & $2.9-3.3$ & $2.9-3.1$ \\
$\mathrm{H}$ & $1.44-1.50$ & $2.06-2.17$ \\
\hline
\end{tabular}

number of pairs of records of horizontal vibration accelerations (in both vibration directions: parallel to the $x$ and $y$ axis of each building-see Fig. 1) in the successive ranges of $r e$, the ranges of $E n$ and $P G A$. The orders of magnitude of rockburst energy levels of $10^{6} \mathrm{~J}, 10^{7} \mathrm{~J}, 10^{8} \mathrm{~J}, 10^{9} \mathrm{~J}$ are denoted as E6, E7, E8, and E9, respectively.

Figure 3 shows example records of horizontal components $x$ and $y$ of free-field vibrations ( $a_{g x}$ and $a_{g y}$, respectively) and simultaneously recorded vibrations of building 
Table 3 Number of

simultaneously measured pairs of records of horizontal vibration accelerations of the free-field vibrations next to the buildings and the building foundations in the successive ranges of $r e, E n$ and $P G A$

\begin{tabular}{|c|c|c|c|c|}
\hline \multicolumn{2}{|l|}{ Parameter ranges } & \multicolumn{3}{|c|}{ Building } \\
\hline & & $\mathrm{L}$ & M & $\mathrm{H}$ \\
\hline \multirow[t]{4}{*}{$r e[\mathrm{~m}]$} & To 700 & 18 & 13 & 9 \\
\hline & $701-1500$ & 3 & 35 & 63 \\
\hline & $1501-2500$ & 2 & 34 & 24 \\
\hline & Over 2501 & 1 & 25 & 24 \\
\hline \multirow[t]{4}{*}{$E n[\mathrm{~J}]$ - order of magnitude } & E6 & 11 & 30 & 24 \\
\hline & E7 & 9 & 53 & 62 \\
\hline & E8 & 4 & 18 & 32 \\
\hline & E9 & - & 6 & 2 \\
\hline \multirow[t]{4}{*}{$P G A\left[\mathrm{~m} / \mathrm{s}^{2}\right]$} & To 0.300 & 12 & 67 & 86 \\
\hline & $0.301-0.600$ & 6 & 24 & 19 \\
\hline & $0.601-0.900$ & 2 & 5 & 8 \\
\hline & Over 0.900 & 4 & 11 & 7 \\
\hline whole ranges of re, En, $P G A$ & & 24 & 107 & 120 \\
\hline
\end{tabular}

(a)
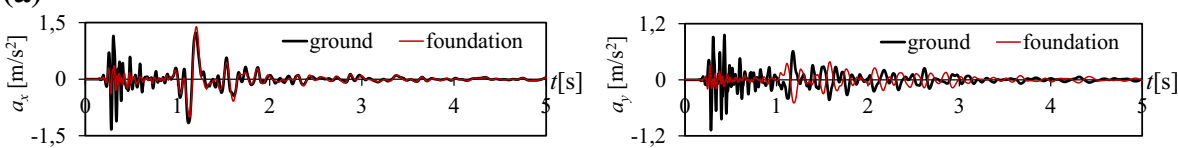

(b)
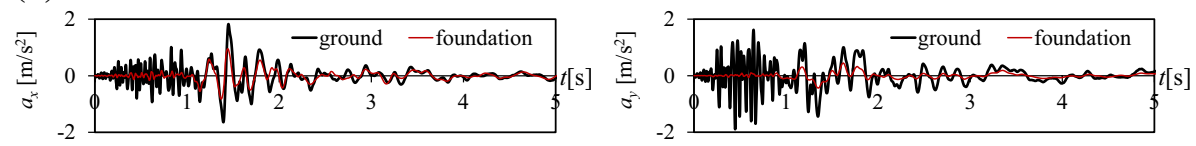

(c)
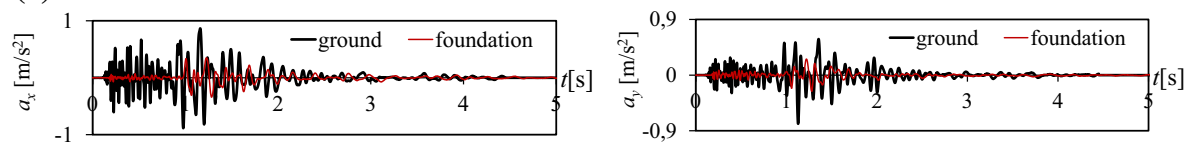

Fig. 3 Example records of horizontal components $a_{g x}, a_{g y}$ of free-field vibrations and simultaneously recorded vibrations $a_{f x}, a_{f y}$ of building L, M and $\mathrm{H}$ foundations: a building $\mathrm{L} ; \mathbf{b}$ building $\mathrm{M} ; \mathbf{c}$ building $\mathrm{H}$

foundations $\mathrm{L}, \mathrm{M}$ and $\mathrm{H}\left(a_{f x}, a_{f y}\right.$ respectively). The results of the frequency analysis of records shown in Fig. 3 using the FFT, are presented in Fig. 4.

\section{Dimensional response spectra $\left(S_{a}\right)$ from mine-induced tremors in LGC}

All the recorded free-field and buildings foundation vibration accelerations $(2 \times 251$ records of vibrations) were used to determine the dimensional response spectra $\left(S_{a}\right)$, and next, to calculate the average response spectra for the successive ranges of $r e, E n$ and 
(a)

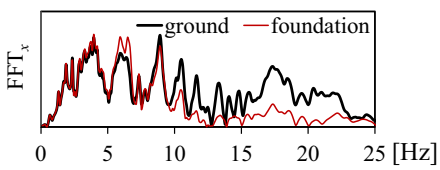

(b)

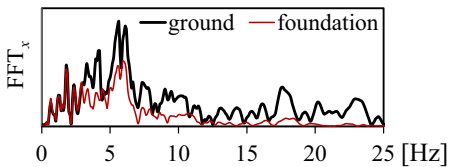

(c)

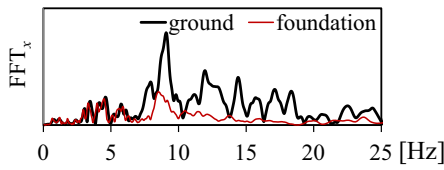

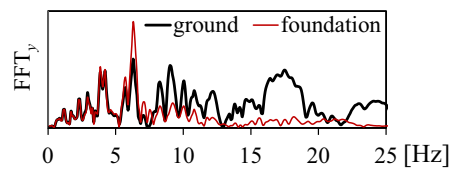
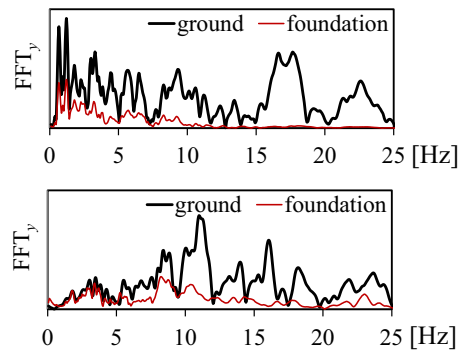

Fig. 4 Fourier spectra from the accelerations presented in: a Fig. 3a; b Fig. 3b; c Fig. 3c

$P G A$. According to the results of experimental analysis relating to the considered buildings, the fraction of critical damping $\xi$ was adopted equal to $3 \%$ (Ciesielski et al. 1995). It is worth mentioning that response spectra referring to earthquakes are usually presented as functions of periods, but because of the content of shorter dominant periods of mining-related vibrations, we decide to present response spectra as the functions of frequencies. Averaged $S_{a}$ calculated using free-field and building foundation vibrations for the considered ranges of re, En and $P G A$ of mining tremors, are shown in Figs. 5 and 6 , respectively.

Using free-field vibrations and taking into account the influence of the re on the $S_{a}$, one can see that the highest spectral values occur at high frequencies in the range of $15-20 \mathrm{~Hz}$ (see Fig. 5a). The maximum values of the spectra calculated depending on the En, are also achieved for frequencies from the band 15 to $20 \mathrm{~Hz}$ (see Fig. $5 \mathrm{~b}$ ). The dominant part of the $S_{a}$ corresponding to greater energy levels of shocks is wider. Then, both low frequencies (from about 6 to $10 \mathrm{~Hz}$ ) and frequencies between about 17 to $23 \mathrm{~Hz}$ dominate. In this case, one must be very careful with drawing generalised conclusions because of the small number of analysed phenomena with the highest energy levels. If we analyse spectral curves calculated in relation to $P G A$, similar trends are observed as in the case of curves obtained depending on the $E n$ for higher frequencies (see Fig. 5b, c). In the case of shocks resulting in the highest $P G A$, exceeding $0.9 \mathrm{~m} / \mathrm{s}^{2}$,

(a)

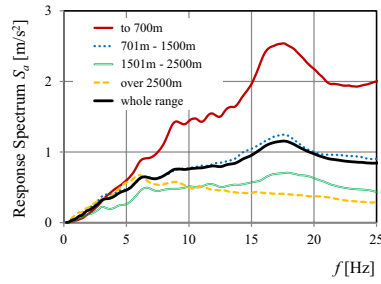

(b)

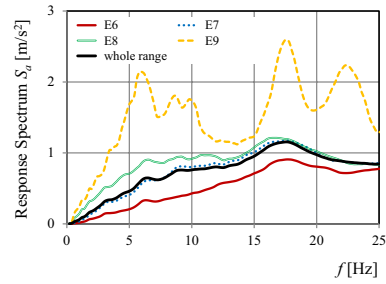

(c)

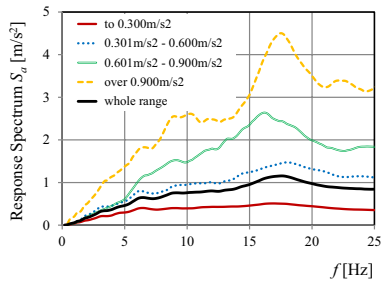

Fig. 5 Average $S_{a}$ calculated using free-field vibrations for the considered ranges of $r e(\mathbf{a}), E n(\mathbf{b})$ and $P G A$ (c) of the analysed mining tremors 
(a)

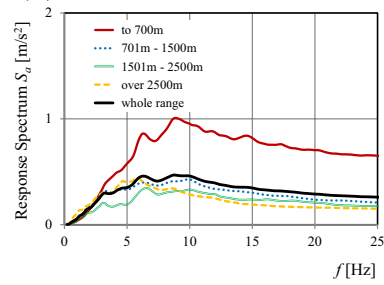

(b)

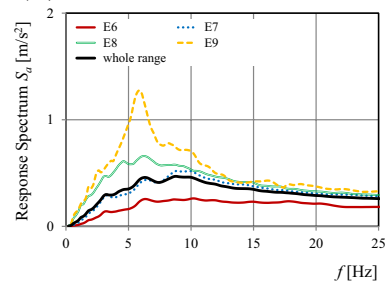

(c)

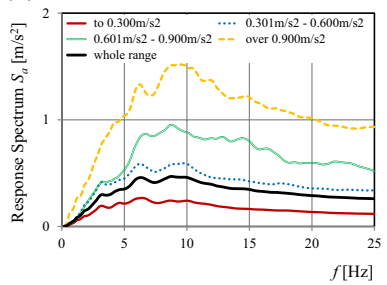

Fig. 6 Average $S_{a}$ calculated using building foundations vibrations for the considered ranges of $r e$ (a), En (b) and $P G A$ (c) of the analysed mining tremors

two dominating frequency bands are visible in which the spectral values reach maximum values. The lower frequency band is in the range 8.5 to $10.5 \mathrm{~Hz}$ and higher is from 17.5 to $22.5 \mathrm{~Hz}$ (see Fig. 5c).

Response spectra $\left(S_{a}\right)$, calculated using building foundation vibrations and taking into account re, En of shocks and $P G A$, are significantly different to response spectra calculated on the basis of free-field vibrations. In these spectra, dominant frequencies are lower than in the spectra calculated on the basis of free-field vibrations. Therefore, the observation can be formulated-the building works as a low-pass filter. This phenomenon is particularly evident when the influence of $r e$ and En levels on spectral curves is considered (see Fig. 6a, b). A wider band of dominant frequencies (from 6 to $10 \mathrm{~Hz}$ ) is observed in the case of the analysis of the impact of $P G A$ on the spectral curves (see Fig. 6c). Figure 6b shows a trend that the higher the En, the lower dominant frequencies.

\section{The influence of mining tremor parameters on the ratio of response spectra (RRS)}

Dimensional acceleration spectra $\left(S_{a}\right)$ from simultaneously recorded free-field vibrations next to the building and foundations of the building were used to assess the transmission of free-field vibrations to the foundations of the buildings. To evaluate differences between free-field and foundation response spectra, the ratio of response spectra $R R S\left(S_{a}\right)$ was calculated in the case of each pair of response spectra determined according to the above key (free-field—building foundation). Thus, formula (1) is used:

$$
R R S\left(S_{a}\right)=\frac{S_{a f}}{S_{a g}}
$$

where: $S_{a f}, S_{a g}$-dimensional acceleration response spectrum from the building foundation vibrations and free-field vibrations next to the building, respectively.

By using the RRS relations in all individual mining shocks, the average $R R S$ values for particular, various types of buildings ( $\mathrm{L}, \mathrm{M}$, and $\mathrm{H}$ ), can be determined.

Separately, in the case of each of the analysed buildings (L, M and H), each curve of the ratios $R R S\left(S_{a}\right)$ defined for each of the considered mining shocks, is placed into one of four sets. The re, En, PGA were the parameters for assigning curves to one of these four groups. Successive ranges of the parameters which correspond to the created relationship 
(a)

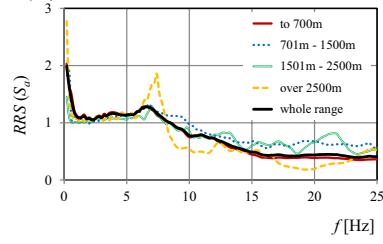

(b)

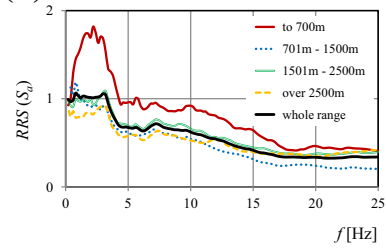

(c)

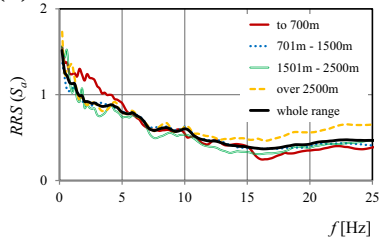

Fig. 7 Curves of $\operatorname{RRS}\left(S_{a}\right)$ averaged in the consecutive ranges of mining tremor epicentral distances (re) in the case of building $\mathrm{L}(\mathbf{a})$, building $\mathrm{M}(\mathbf{b})$, building $\mathrm{H}(\mathbf{c})$

(a)

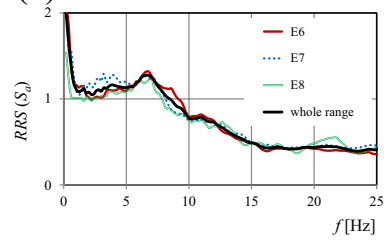

(b)

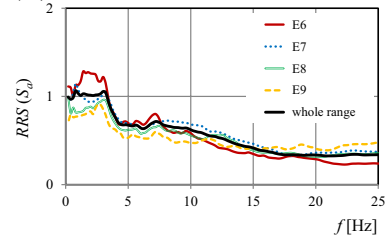

(c)

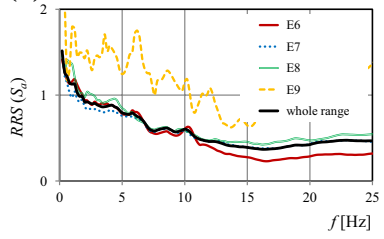

Fig. 8 Curves of $\operatorname{RRS}\left(S_{a}\right)$ averaged in the consecutive orders of magnitude of $E n$ levels in the case of building $\mathrm{L}(\mathbf{a})$, building $\mathrm{M}(\mathbf{b})$, building $\mathrm{H}(\mathbf{c})$

(a)

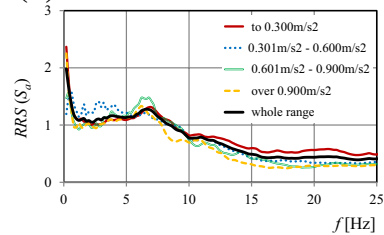

(b)

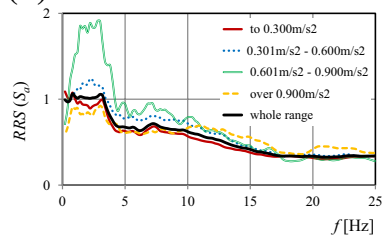

(c)

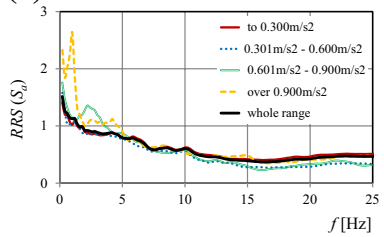

Fig. 9 Curves of $R R S\left(S_{a}\right)$ averaged in the consecutive ranges of $P G A$ in the case of building L (a), building $\mathrm{M}(\mathbf{b})$, building $\mathrm{H}(\mathbf{c})$

groups $R R S$, are presented in Table 3. The averaged $R R S$ were determined in each set of relationship $R R S\left(S_{a}\right)$. The averaged curves of $R R S$ correspond to the successive mining tremor parameters and to their successive ranges, respectively. Figure 7 shows the individual $\operatorname{RRS}\left(S_{a}\right)$ for the buildings $\mathrm{L}, \mathrm{M}$ and $\mathrm{H}$, averaged within the considered ranges of re of mine-induced tremors. As with the analysis of the influence of the rockburst's $r e$ on the ratios of response spectra, the curves of $R R S\left(S_{a}\right)$ averaged for the successive orders of magnitude of $E n$ levels and the ranges of $P G A$ are shown in Figs. 8 and 9, respectively.

Relatively small differences in the curves $\operatorname{RRS}\left(S_{a}\right)$ obtained by averaging of the collections referring to individual ranges of mining tremors parameters, are visible in the cases of all considered apartment buildings: L, M, H (see Figs. 7, 8, 9). Furthermore, the graphs of $R R S\left(S_{a}\right)$ made for the individual ranges of the considered parameters (re, En, PGA) do not differ much from curves averaged across all ranges of the parameter values.

Very clear trend concerns the relationship between re, En, $P G A$ and $R R S\left(S_{a}\right)$ curves, can be observed in Figs. 7, 8 and 9: the smaller the values of $R R S\left(S_{a}\right)$, the greater the vibration frequency $f$ in the case of each type of the analysed buildings. 
Fig. 10 Averaged curves of $R R S\left(S_{a}\right)$ for buildings $\mathrm{L}, \mathrm{M}$ and $\mathrm{H}$

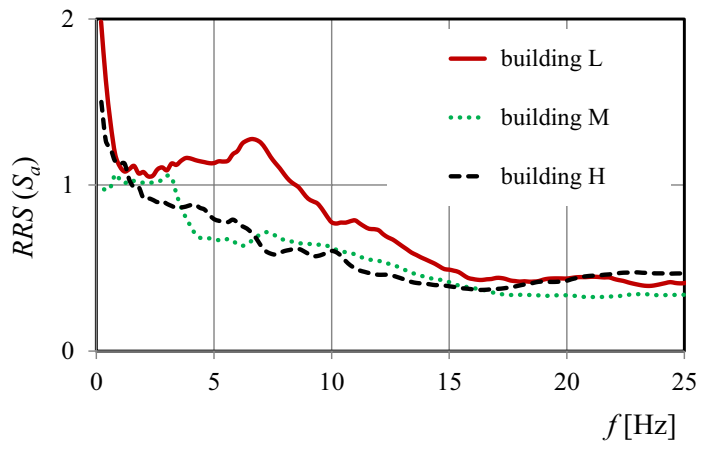

Table 4 Values of relation (ratio) $\operatorname{RRS}\left(S_{a}\right)$ for buildings L, M and $\mathrm{H}$ corresponding to fundamental natural frequencies of buildings in consecutive ranges of $r e, E n$ and $P G A$

\begin{tabular}{lllll}
\hline Building $\left(f_{1}[\mathrm{~Hz}]\right)$ & & $\mathrm{L}(6.3 \mathrm{~Hz})$ & $\mathrm{M}(3.0 \mathrm{~Hz})$ & $\mathrm{H}(1.8 \mathrm{~Hz})$ \\
\hline re $[\mathrm{m}]$ & To 700 & 1.27 & 1.68 & 1.23 \\
& $701-1500$ & 1.21 & 0.92 & 0.92 \\
& $1501-2500$ & 1.09 & 1.07 & 1.07 \\
& Over 2500 & 1.26 & 0.90 & 0.98 \\
En $[\mathrm{J}]$-order of magnitude & E6 & 1.26 & 1.22 & 1.01 \\
& E7 & 1.26 & 1.02 & 0.95 \\
& E8 & 1.21 & 0.96 & 1.02 \\
& E9 & - & 0,85 & 1.49 \\
& To 0.300 & 1.21 & 0.98 & 0.98 \\
& $0.301-0.600$ & 1.19 & 1.16 & 0.88 \\
& $0.601-0.900$ & 1.48 & 1.91 & 1.20 \\
whole ranges of $r e, E n, P G A$ & Over 0.900 & 1.33 & 0.92 & 1.09 \\
\hline
\end{tabular}

Practically, in most of the individual ranges of the considered mining tremors parameters (re, En, PGA) one can't see significant dependence of the scale of differences in the relationship $R R S\left(S_{a}\right)$ referring different constructions of buildings L, M and H. However, in general, it can be stated that the influence of the building structure on the form of the ratio response spectra curve can be observed. These differences are clearly evident in the case of averaged curves $\operatorname{RRS}\left(S_{a}\right)$ computed for the corresponding pairs of dimensional spectra $S_{a}$ (see Fig. 10).

Furthermore, the analysis is focused on the differences in the values of $R R S$ corresponding to the fundamental natural frequencies of building vibrations, calculated for the individual ranges of mining tremor parameters. Table 4 contains the values of $R R S\left(S_{a}\right)$ corresponding to the fundamental frequencies of natural vibrations $f_{1}$ of $\mathrm{L}, \mathrm{M}$ and $\mathrm{H}$ buildings, averaged for the successive ranges of these rockbursts parameters. Results of the analysis indicate that in the medium-rise building (building $\mathrm{M}$ ) and high-rise building (building $\mathrm{H}$ ), the spectral values from the free-field are transmitted practically unchanged to the buildings foundations. A slightly larger difference was obtained for the low-rise building (building L). The difference is approximately $25 \%$ (see Table 4 ). 
(a)

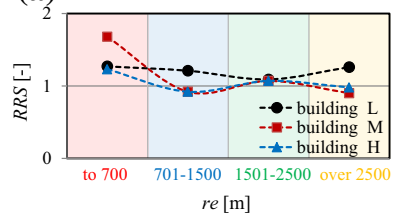

(b)

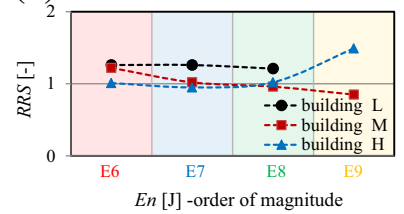

(c)

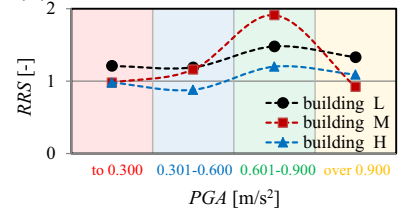

Fig. 11 Values of relation (ratio) $R R S\left(S_{a}\right)$ for building $\mathrm{L}$, building $\mathrm{M}$ and building $\mathrm{H}$ determined for the first vibration frequencies of the buildings in a function of the considered ranges of re (a), En (b), and PGA (c)

Nevertheless, one can see significant differences in the ordinates of $\operatorname{RRS}\left(S_{a}\right)$ calculated for the fundamental natural frequencies of the buildings in the consecutive ranges of the considered mining tremor parameters: re, En, $P G A$. For instance, in the case of building $\mathrm{M}$, the values of $\operatorname{RRS}\left(S_{a}\right)$ calculated for $r e$ of up to $700 \mathrm{~m}$ are almost twice as great as the comparable values specified for re over $2500 \mathrm{~m}$. In the cases of $R R S\left(S_{a}\right)$ averaged for the consecutive orders of magnitude of En, successive ranges of $r e$ or successive ranges of $P G A$, are differentiated depending on the type of building.

Furthermore, from the comparison of the values of $\operatorname{RRS}\left(S_{a}\right)$ determined for the fundamental natural frequencies of building vibrations in the successive, individual ranges of each considered parameter of mining tremors, in relation to the averaged values of $\operatorname{RRS}\left(S_{a}\right)$ using all of the $R R S$ curves (without distinction between the parameter ranges), one can see that the differences can reach: building $\mathrm{L}, \operatorname{RRS}\left(S_{a}\right)$-approx. $18 \%$; building $\mathrm{M}, \operatorname{RRS}\left(S_{a}\right)$ approx. $80 \%$; building $\mathrm{H}, \operatorname{RRS}\left(S_{a}\right)$-approx. $51 \%$.

Using the data from Table 4, the mean values of $R R S\left(S_{a}\right)$ for buildings $\mathrm{L}, \mathrm{M}, \mathrm{H}$ depending on the $r e$ of the analysed shocks and concerning to the fundamental vibration frequency of each building, are shown in Fig. 11a. The $R R S\left(S_{a}\right)$ values corresponding to fundamental natural frequency of building $\mathrm{L}$ are practically stable throughout the analysed range of epicentral distances. But there are noticeable differences in the $\operatorname{RRS}\left(S_{a}\right)$ values corresponding to the analysed range of epicentral distances in the case of building M. The $R R S\left(S_{a}\right)$ values for all buildings ( $\left.\mathrm{L}, \mathrm{M}, \mathrm{H}\right)$ are practically constant in the case of energy magnitude up to E8 (see Fig. 11b). In the case of $R R S\left(S_{a}\right)$ corresponding to the building's natural frequencies of horizontal vibrations, depending on the $P G A$, there is a significant difference compared to the relationships occurring in the study of the effect of re and En-compare Fig. 11a, b with Fig. 11c. The values of ratio $R R S\left(S_{a}\right)$ determined for the first vibration frequencies of the buildings, are characterised by high sensitivity to the influence of the $P G A$ level, see Fig. 11c. The maximum values of the $R R S\left(S_{a}\right)$, occur for rockbursts with $P G A$ values in the range $0.601-0.900 \mathrm{~m} / \mathrm{s}^{2}$ for all analysed buildings, see Fig. 11c.

Figure 12 shows the averaged generalised relations $\operatorname{RRS}\left(S_{a}\right)$ obtained for the fundamental natural frequencies of the buildings, taking into account all analysed vibration records across the entire ranges of re, En and PGA, see Table 4. Consistently, relation $R R S\left(S_{a}\right)$ is characterised by its low variability of values corresponding to the fundamental natural frequencies of the buildings. Furthermore, the $R R S\left(S_{a}\right)$ values are characterised by great stability. This observation may be a justification for using model spectra from ground response in seismic analyses. 
Fig. 12 Change in values of relation (ratio) $R R S\left(S_{a}\right)$ for building $\mathrm{L}, \mathrm{M}$ and $\mathrm{H}$ determined for the first vibration frequencies of the buildings in the whole ranges of re, En and $P G A$

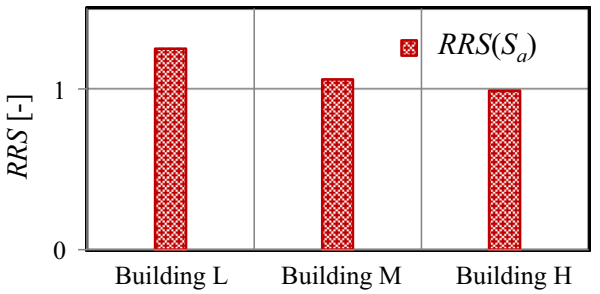

\section{Simple soil-structure interaction (SSI) models}

\subsection{Evaluation of the usefulness of SSI models proposed for earthquakes in the case of mining shocks}

In the literature, theoretical works dominate in the area of soil-structure interaction problem. Experimental studies regarding this issue are more modest in number. An alternative way of solving the problem may be the use of simple approximate models to assess the transfer of vibrations from the free-field to the building foundations; this is convenient in practical applications. For instance, the U.S. National Institute of Standards and Technology elaborated SSI models and put them into use in the case of seismic data (FEMA 2005; NIST GCR 2012). Mining-related free-field vibrations are in many respects similar to vibrations of earthquake origin. Therefore, it is interesting to evaluate the suitability of some models proposed for vibrations of seismic origin (e.g. FEMA 2005; NIST GCR 2012) in the case of mine-related vibrations in the LGC region (Kuzniar and Tatara 2015).

In order to analyse the possible usefulness of simple, approximate, convenient empirical SSI models that have been prepared for earthquakes in the cases of mining tremors in the LGC region, it was decided to consider the type of models prepared by the U.S. National Institute of Standards and Technology (NIST GCR 2012).

These models in accordance with the indications from NIST GCR (2012) are marked as $H_{u}$ and $R R S$. The $H_{u}$ model is called as the transfer function, and the $R R S$ model is called as the ratio of response spectra. Equations (2)-(5) show the $H_{u}$ transformation function (NIST GCR 2012).

$$
\begin{gathered}
H_{u}=\frac{S_{a f}}{S_{a g}} \\
H_{u}=H_{u b s a} \cdot H_{\text {uemb }} \\
H_{u b s a}=\frac{\sin \left(a_{0}^{k} \cdot \frac{V_{s}}{V_{a p p}}\right)}{a_{0}^{k} \cdot \frac{V_{s}}{V_{a p p}}}, \quad \text { for } a_{0}^{k} \leq \frac{\pi}{2} \cdot \frac{V_{a p p}}{V_{s}} \\
H_{u b s a}=\frac{2}{\pi}, \quad \text { for } \quad a_{0}^{k}>\frac{\pi}{2} \cdot \frac{V_{a p p}}{V_{s}} \\
a_{0}^{k}=\frac{\omega \cdot B_{e}^{A}}{V_{s}}
\end{gathered}
$$




$$
\begin{gathered}
H_{\text {uemb }}=\cos \left(\frac{D \cdot \omega}{V_{s}}\right), \quad \text { for } \quad \frac{D \cdot \omega}{V_{s}}<1.1 \\
H_{\text {uemb }}=0.45, \quad \text { for } \quad \frac{D \cdot \omega}{V_{s}}>1.1
\end{gathered}
$$

where $H_{u b s a}$-function taking into account the modification of surface vibrations due to the foundation of the building in relation to the surface vibrations occurring in the absence of the structure; $H_{\text {uemb }}$ - function that takes into account the depth of the footing of foundations; $\omega$-circular natural frequency of the structure: $\omega=2 \pi f ; f$-natural frequency of the structure $[\mathrm{Hz}] ; V_{s}$-shear wave velocity $[\mathrm{m} / \mathrm{s}] ; V_{a p p}$-apparent velocity of wave propagation $[\mathrm{m} / \mathrm{s}] ; B_{e}^{A}$ - half of the side dimension of a square with an area equivalent to the area of the actual foundation of the structure $\left(\right.$ Area $\left.=\left(2 B_{e}^{A}\right)^{2}\right)[\mathrm{m}]$ (note that in the case of average spectra obtained from records regarding the various types of buildings together, this parameter is the average value for the all buildings); $D$ —depth of foundation [m].

Finally, according to the practical procedures recommended in the NIST report (NIST GCR 2012), it was decided to use the simplified form of RRS model. According to this report (NIST GCR 2012), the RRS model can be described with the application of the transfer function $H_{u}$ as follows:

$$
\begin{gathered}
R R S \approx H_{u}(f), \quad \text { for } \quad f<f_{L} \\
R R S \approx H_{u}\left(f_{L}\right), \quad f \geq f_{L}
\end{gathered}
$$

where: $f_{L}$-limiting frequency $[\mathrm{Hz}]$.

In both models $\left(H_{u}\right.$ and $\left.R R S\right)$, the average value of $V_{s}=200 \mathrm{~m} / \mathrm{s}$ was adopted according to the ground conditions in the LGC region (Dubinski et al. 2006). The value of $f_{L}=10 \mathrm{~Hz}$ was assumed in accordance with the mean value of the predominant frequencies of free-field vibrations in the LGC area. It is worth noting that for earthquakes in which the dominant free-field vibration frequencies are lower, the value of $f_{L}=5 \mathrm{~Hz}$ is proposed (FEMA 2005).

Taking into account the ground conditions in the LGC region and the $P G A$ in this area, according to the guidelines from the NIST report (NIST GCR 2012), we assume in the calculations that the reduced velocity of shear wave $\left(V_{s r}\right)$ equals the shear wave velocity $\left(V_{s}\right)$ : $V_{s r}=V_{s}$. In accordance with the NIST report (NIST GCR 2012), the approximate relationship- $V_{a p p} / V_{s}=10$ - was assumed in the calculations.

Fig. 13 Ratio $R R S\left(S_{a}\right)$ from mining tremors based on the averaged response spectra taking into account all of the considered $\mathrm{L}, \mathrm{M}$, and $\mathrm{H}$ buildings, compared to $H_{u}$ and $R R S$ models

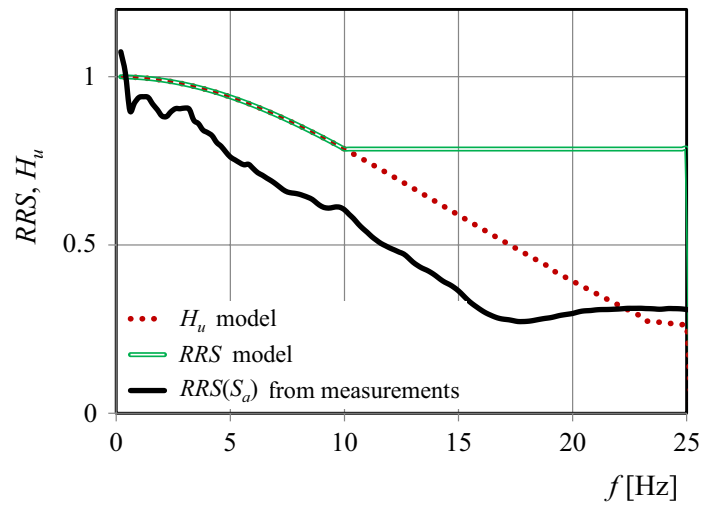


(a)

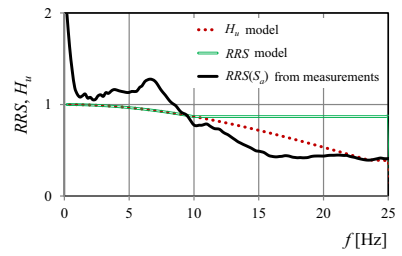

(b)

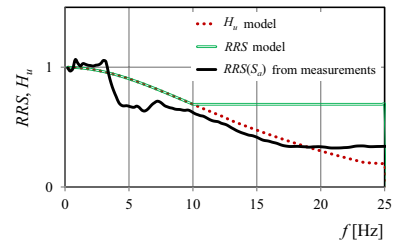

(c)

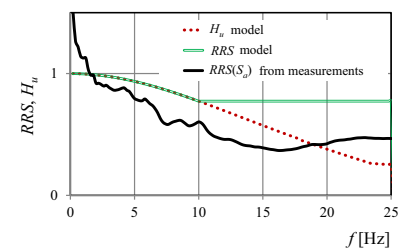

Fig. 14 Ratio $\operatorname{RRS}\left(S_{a}\right)$ from mining tremors based on the averaged response spectra, compared to $H_{u}$ and $R R S$ models for building $\mathrm{L}(\mathbf{a})$, building $\mathrm{M}(\mathbf{b})$ and building $\mathrm{H}$ (c)

Table 5 Pearson correlation coefficient $(r)$, mean squared error (MSE) as well as root mean squared error $(R M S E)$ of the $H_{u}$ and $R R S$ models, compared with the data from mine-induced vibration measurements

\begin{tabular}{|c|c|c|c|c|c|c|}
\hline \multirow[t]{2}{*}{ Building } & \multicolumn{2}{|l|}{$r$} & \multicolumn{2}{|l|}{$M S E$} & \multicolumn{2}{|l|}{$R M S E$} \\
\hline & $H_{u}$ model & $R R S$ model & $H_{u}$ model & $R R S$ model & $H_{u}$ model & $R R S$ model \\
\hline $\mathrm{L}$ & 0.879 & 0.863 & 0.0358 & 0.1120 & 0.1893 & 0.3347 \\
\hline M & 0.936 & 0.906 & 0.0107 & 0.0626 & 0.1035 & 0.2503 \\
\hline $\mathrm{H}$ & 0.775 & 0.943 & 0.0310 & 0.0827 & 0.1760 & 0.2877 \\
\hline $\mathrm{L}, \mathrm{M}, \mathrm{H}$ & 0.931 & 0.927 & 0.0277 & 0.1248 & 0.1664 & 0.3533 \\
\hline
\end{tabular}

In Fig. 13, ratio $R R S\left(S_{a}\right)$ from mining tremors based on the averaged response spectra, taking into account the considered $\mathrm{L}, \mathrm{M}$, and $\mathrm{H}$ buildings together, is compared to $H_{u}$ and $R R S$ models. It is worth mentioning that the ratios are not obtained from averaged ratios for each of the buildings - the $R R S\left(S_{a}\right)$ graph is obtained using the averaged response spectra from all the analysed free-field records and building foundation records, irrespective of the building type. Ratios $R R S\left(S_{a}\right)$ based on the averaged response spectra prepared separately for building L, building $\mathrm{M}$ and building $\mathrm{H}$, are compared to $H_{u}$ and $R R S$ models in Fig. 14. Additionally, Pearson correlation coefficients $(r)$, mean squared error $(M S E)$ and root mean squared error (RMSE) presented in Table 5, can be helpful in the estimation of the possible usefulness of $H_{u}$ and $R R S$ models (constructed on the basis of earthquake data) in the cases of mine-related rockbursts.

It can be stated that both models $\left(H_{u}\right.$ and $\left.R R S\right)$ allow the prediction of the trends of experimentally determined SSI effects in the LGC mining region, with a relatively strong correlation. This applies to a similar degree, to ratios $R R S\left(S_{a}\right)$ corresponding to all buildings analysed together, and separately for building $\mathrm{L}$, building $\mathrm{M}$ and building $\mathrm{H}$. However, some deviations from the experimentally obtained values of ratio $\operatorname{RRS}\left(S_{a}\right)$ can be observed in the cases of the models. These differences in the ratio of response spectra values can be explained by differences between mine-induced and seismic motions. Generally, it is difficult to determine which of the models leads to more accurate predictions, and with which of the above mentioned simple models the transmission of spectra $S_{a}$ is easier to predict.

\subsection{Empirical simple models for the determination of ratios of response spectra (RRS) in the LGC region}

Because of some possible inaccuracies of the predictions of mine-related $\operatorname{RRS}\left(S_{a}\right)$ values using the approximate models constructed for earthquakes, in this paper, we propose 
Table 6 Equations of the designed empirical models of $R R S\left(S_{a}\right)$ intended for the LGC area

\begin{tabular}{llll}
\hline Building & Model & Equations of the models & \\
\cline { 3 - 4 } & & $f<15 \mathrm{~Hz}$ & $f \geq 15 \mathrm{~Hz}$ \\
\hline L, M, H & S.0 & $-0.0007 f^{2}-0.0304 f+0.9903$ & 0.377 \\
L & S.L & $-0.0032 f^{2}-0.0070 f+1.2669$ & 0.442 \\
M & S.M & $-0.0003 f^{2}-0.0355 f+1.0078$ & 0.408 \\
H & S.H & $0.0023 f^{2}-0.0861 f+1.1720$ & 0.398 \\
\hline
\end{tabular}

Fig. 15 Ratio $\operatorname{RRS}\left(S_{a}\right)$ from mining tremors based on the averaged response spectra taking into account $\mathrm{L}, \mathrm{M}$, and $\mathrm{H}$ buildings together, compared to proposed model S.0

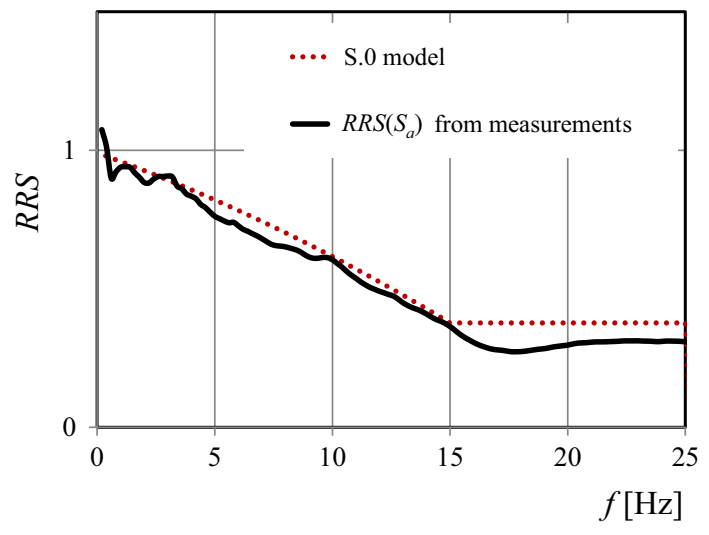

similar, simple, easy-to-use models intended for mine-induced rockbursts in the LGC region-models $R R S\left(S_{a}\right)$ (Kuzniar and Tatara 2017). The models are designed in two variants: (a) 'universal' model intended for use in the cases of all of the types of apartment buildings (regardless of the size); (b) separate models for use specifically with the different types of apartment buildings in the mining region- $-\mathrm{L}, \mathrm{M}$, and $\mathrm{H}$. These models correspond to the nature of rockbursts which induce vibrations and the characteristic of subsoil in the LGC region.

From important observation which applies to $\operatorname{RRS}\left(S_{a}\right)$, is can be stated that the averaged plots of the RRS prepared separately for buildings of different types $(\mathrm{L}, \mathrm{M}, \mathrm{H})$, are different see, for example, Fig. 10. Moreover, it is also clearly visible that for frequencies higher than $15 \mathrm{~Hz}$, the values of $R R S$ are nearly constant regardless of the case of calculated curve, see, for example, Figs. 13 and 14.

The model for $\operatorname{RRS}\left(S_{a}\right)$, which has been developed for use in the cases of all types of buildings ('universal' model), is denoted as S.0 model. Whereas the models designed for separate application in the case of each type of apartment building (L, M and H) are denoted as: S.L model, S.M model, and S.H model. Equations of the above-mentioned models are given in Table 6, and their graphical comparisons with the curves experimentally determined on the basis of acceleration vibration records measured on the free-field near the buildings and on the buildings foundations, are shown in Figs. 15 and 16. The accuracy of the proposed models in the case of using them as a possible, simple tool for the prediction of differences in the free-field and building foundation mine-induced vibrations, was assessed using a linear Pearson correlation coefficient, mean squared error (MSE) and root mean squared error (RMSE). Table 7 contains these values (which allow the easy description and evaluation of errors of model predictions) in the case of the average 
(a)

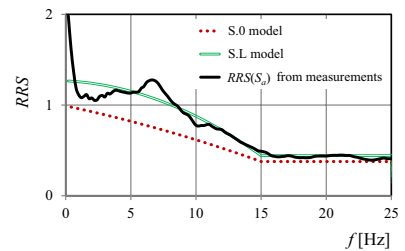

(b)

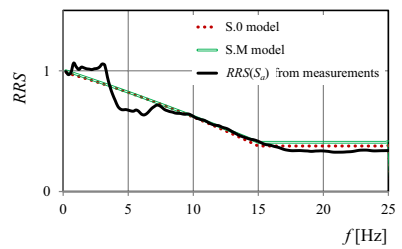

(c)

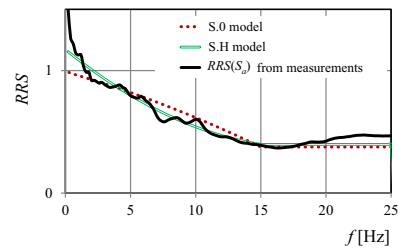

Fig. 16 Ratio $R R S\left(S_{a}\right)$ from mining tremors based on the averaged response spectra, compared to models proposed for building $\mathrm{L}(\mathbf{a})$, building $\mathrm{M}(\mathbf{b})$, building $\mathrm{H}(\mathbf{c})$

Table 7 Pearson correlation coefficient $(r)$, mean squared error (MSE) as well as root mean squared error (RMSE) of the proposed $R R S\left(S_{a}\right)$ models, compared with the data from mine-induced vibration measurements

\begin{tabular}{lllll}
\hline Building & Model & $r$ & MSE & $R M S E$ \\
\hline L, M, H & S.0 & 0.994 & 0.0034 & 0.0581 \\
L & S.0 & 0.948 & 0.0569 & 0.2386 \\
& S.L & 0.955 & 0.0102 & 0.1012 \\
M & S.0 & 0.964 & 0.0041 & 0.0641 \\
& S.M & 0.966 & 0.0052 & 0.0717 \\
H & S.0 & 0.929 & 0.0074 & 0.0863 \\
& S.H & 0.974 & 0.0029 & 0.0537 \\
\hline
\end{tabular}

relation $\operatorname{RRS}\left(S_{a}\right)$. The results are given for the proposed models, also for the 'universal' model (S.0 model) applied in the case of data related separately to each type of building.

A high level of compatibility of models constructed for use separately in the case of different types of buildings with the actual effect of the transmission of the dimensional spectra $\left(S_{a}\right)$ is visible. However, even the 'universal' model (S.0 model) allows the prediction of the averaged $R R S\left(S_{a}\right)$ values with satisfactory levels of accuracy despite the fact that it is not taking into account information about the differences in building structures (and therefore also dynamic properties of the buildings). Moreover, the accuracy of the all models is not lost despite assuming the constant value of $R R S$ for frequencies exceeding $15 \mathrm{~Hz}$.

\section{Conclusions}

By comparing the response spectra calculated on the basis of the pairs of free-field-foundation records, one can conclude that the free-field and foundation response spectra differ significantly. Moreover, a strong dependence of the forms of response spectra curves on epicentral distances, energy levels and on peak ground accelerations is visible in the case of response spectra determined from both free-field and foundation vibrations. The analogous and important in practice conclusion applies to the curves of ratios of response spectra. Furthermore, it is stated that the influence of building structure on the form of ratio of response spectra curves can be clearly observed.

The possibility of using approximate, simple models which take into account the phenomenon of soil-structure interaction and the usefulness of such models designed for the analysis of earthquakes, is verified in the case of mining tremors. This assessment leads to 
the conclusion that despite the differences between seismic and mine-induced vibrations, the models correctly predict the trends of the ratio of response spectra curves. However, because of some inaccuracies found in the values of ratios of response spectra obtained using the models for earthquakes in comparison with experimental data regarding mining tremors, we propose empirical models intended just for mining tremors in the LGC region. Satisfactory accuracy in the application of the designed models is confirmed.

Open Access This article is distributed under the terms of the Creative Commons Attribution 4.0 International License (http://creativecommons.org/licenses/by/4.0/), which permits unrestricted use, distribution, and reproduction in any medium, provided you give appropriate credit to the original author(s) and the source, provide a link to the Creative Commons license, and indicate if changes were made.

\section{References}

Ahmadi E (2019a) On the structural energy distribution and cumulative damage in soil-embedded foundation-structure interaction systems. Eng Struct 182:487-500. https://doi.org/10.1016/j.engst ruct.2018.12.091

Ahmadi E (2019b) Concurrent effects of inertial and kinematic soil-structure interactions on strengthductility-period relationship. Soil Dyn Earthq Eng 117:174-189. https://doi.org/10.1016/j.soild yn.2018.10.043

Arjang B, Herget G (1997) In situ ground stresses in the Canadian hardrock mines: an update. Int J Rock Mech Min Sci 34:15.e1-15.e16

Ciesielski R, Kuzniar K, Maciag E, Tatara T (1995) Damping of vibration in precast buildings with bearing concrete walls. Archives of Civil Eng 41:329-341

Deck O, Heib MA, Homand F (2003) Taking the soil-structure interaction into account in assessing the loading of a structure in a mining subsidence area. Eng Struct 25:435-448

Dubinski J, Lurka A, Stec K (2006) Investigation of the relationship between seismic radiation pattern and focal mechanism of the seismic events (in Polish). In: Proceedings workshop: natural hazards in mining. Krakow, Poland

EN 1998-1 Eurocode 8 (2004) Design of structures for earthquake resistance-Part 1: General rules, seismic actions and rules for buildings

FEMA 440 (2005) Improvement of nonlinear static seismic analysis procedures, ATC-55 Project

Fu J, Liang J, Todorovska MI, Trifunac MD (2018) Soil-structure system frequency and damping: estimation from eigenvalues and results for a 2D model in layered half-space. Earthq Eng Struct Dyn 47:2055-2075

Furumura T, Takemura S, Noguchi S, Takemoto T, Maeda T, Iwai K, Padhy S (2011) Strong ground motions from the 2011 off-the Pacific-Coast-of-Tohoku, Japan $(\mathrm{Mw}=9.0)$ earthquake obtained from a dense nationwide seismic network. Landslides 8:333-338

GBDS-2018 (2018) Guia Boliviana de diseno sismico V2.0, Version Beta (En fase de consulta publica)

Güllü H, Karabekmez M (2017) Effect of near-fault and far-fault earthquakes on a historical masonry mosque through 3D dynamic soil-structure interaction. Eng Struct 152:465-492

Khosravikia F, Mahsuli M, Ghannad MA (2018) The effect of soil-structure interaction on the seismic risk to buildings. Bull Earthq Eng 16:3653-3673

Konicek P, Soucek K, Stas L, Singh R (2013) Long-hole distress blasting for rockburst control during deep underground coal mining. Int J Rock Mech Min Sci 61:141-153

Kufner SK, Schurr B, Haberland C, Zhang Y, Saul J, Ischuk A, Oimahmadov I (2017) Zooming into the Hindu Kush slab break-off: a rare glimpse on the terminal stage of subduction. Earth Planet Sci Lett 461:127-140

Kuzniar K, Tatara T (2015) Application of approximate SSI models in case of mining tremors. Pol Min Rev 10:25-30

Kuzniar K, Tatara T (2017) Simple models for determination of the differences of ground and building foundation response spectra in LGC region. Tech Trans Civil Eng 1:65-77

Kuzniar K, Stec K, Tatara T (2018) The impact of some parameters of mine-induced rockbursts on the transmission of free-field vibrations to the office building foundation. In: Proceedings 16th European conference on earthquake engineering, Thessaloniki, Greece; ID 10286,1-9 
Li T, Cai MF, Cai M (2007) A review of mining-induced seismicity in China. Int J Rock Mech Min Sci 44:1149-1171

Lovchikov AV (2013) Review of the strongest rockbursts and mining-induced earthquakes in Russia. J Min Sci 49:572-575

Lu CP, Dou LM, Liu B, Xie YS, Liu HS (2012) Microseismic low-frequency precursor effect of bursting failure of coal and rock. J Appl Geophys 79:55-63

Maciag E, Kuzniar K, Tatara T (2016) Response spectra of the ground motion and building foundation vibrations excited by rockbursts in the LGC region. Earthq Spectra 32:1769-1791

Mylonakis G, Nikolaou S, Gazetas G (2006) Footings under seismic loading: analysis and design issues with emphasis on bridge foundations. Soil Dyn Earthq Eng 48:824-853

NIST GCR 12-917-21 (2012) Soil-Structure interaction for building structures, prepared by NEHRP consultants joint venture (The Applied Technology Council and the Consortium of Universities for Research in Earthquake Engineering)

NSR-10 (2010) Normas Colombianas de Diseno y Construccion Sismo Resistente

Olszewska D (2017) The acceleration response spectra for Legnica-Glogow copper district. Tech Trans Civil Eng 9:99-115

Pachla F, Kowalska-Koczwara A, Tatara T, Stypula K (2019) The influence of vibration duration on the structure of irregular RC buildings. Bull Earthq Eng 17:3119-3138

Pineda-Porras OA, Ordaz M (2012) Seismic damage estimation in buried pipelines due to future earthquakes: the case of the Mexico City Water System. Earthquake resistant structures: design, assessment and rehabilitation - chapter 5:131-150, INTECH Open Access Publisher

Poplawski RF (1997) Seismic parameters and rockburst hazard at Mt. Charlotte Mine. Int J Rock Mech Min Sci 34:1213-1228

Singh PK, Roy MP (2010) Damage to surface structures due to blast vibration. Int J Rock Mech Min Sci 47:949-961

Srinivasan C, Arora SK, Benady S (1999) Precursory monitoring of impending rockbursts in Kolar gold mines from microseismic emissions at deeper levels. Int J Rock Mech Min Sci 36:941-948

Steward RA, Reimold WU, Charlesworth EG, Ortlepp WD (2001) The nature of deformation zone and fault rock related to a recent rockburst at Western Deep Levels Gold Mine, Witwatersrand Basin, South Africa. Tectonophysics 337:173-190

The Math Works (2000) Inc MATLAB Signal Processing Toolbox. User's Guide

Zembaty Z (2004) Rockburst induced ground motion—a comparative study. Soil Dyn Earthq Eng 24:11-23

Publisher's Note Springer Nature remains neutral with regard to jurisdictional claims in published maps and institutional affiliations. 